\title{
FLUIDEZ TERRITORIAL E LOGÍSTICA: O PROGRAMA DE ACELERAÇÃO DO CRESCIMENTO (PAC) NO RIO GRANDE DO NORTE
}

\section{Territorial fluidity and logistics: the Growth Acceleration Program (PAC) in Rio Grande do Norte (Brazil)}

\author{
Maxsuel Moura Macedo \\ Universidade Federal do Rio Grande do Norte, Natal, Rio Grande do Norte, Brasil \\ maxsuelmm@yahoo.com.br
}

Artigo recebido em 05/04/2015 e aceito para publicação em 29/09/2015

RESUMO: O Estado é responsável por criar condições normativas e infraestruturais em um determinado território. Contudo, essas ações, em alguns casos, se mostram seletivas e restritas, como no caso das concernentes ao setor de transporte e logística. As ações do Estado brasileiro destinadas à fluidez territorial na atualidade são consubstanciadas, especialmente, pelo Programa de Aceleração do Crescimento (PAC). Dentro desse contexto de transformações territoriais advindas com esse programa, situamos nosso trabalho, que objetiva compreender como as ações do Estado concretizadas e planejadas no âmbito do PAC estão configurando ou podem configurar a logística territorial brasileira, particularmente, a do estado do Rio Grande do Norte.

Palavras-chave: Programa de Aceleração do Crescimento. Logística. Fluidez Territorial. Rio Grande do Norte.

ABSTRACT: The State is responsible for creating regulatory and infrastructural conditions in a given territory. However, these actions, in some cases, show selective and restricted, such as the actions for transport and logistics sector. The Brazilian State's actions for the territorial fluidity are realized through the Growth Acceleration Program (PAC). In this context of territorial changes brought about by the Program, we situate our work, which aims to understand how the State's actions implemented and planned in the PAC's scope are configuring or can configure the Brazilian territorial logistics, particularly the Rio Grande do Norte state.

Keywords: Growth Acceleration Program. Logistics. Territorial Fluidity. Rio Grande do Norte. 


\section{INTRODUÇÃO}

As ações do Estado brasileiro destinadas à fluidez na atualidade são consubstanciadas, especialmente, a partir dos planos de logística, como o Plano Nacional de Logística e Transporte (PNLT), o Programa de Investimento em Logística (PIL), e o Programa de Aceleração do Crescimento (PAC). É a partir deste último que o planejamento se concretiza em sistemas de engenharia.

O presente artigo tem como objetivo analisar algumas ações do Estado realizadas no estado do Rio Grande do Norte no âmbito do PAC para o setor de transporte e logística, com vistas a compreender como os novos sistemas de engenharia e os objetos refuncionalizados configuram a logística territorial do estado em tela.

O Estado é responsável por criar condições normativas e infraestruturais em um determinado território, desta forma, "participa de uma divisão de atividades que atribui aos grandes capitais pequenos riscos, assegurando assim a continuidade e reprodução da divisão desigual de riquezas (...)" (CATAIA, 2011, p.119). Para Habermas (2011) a atividade estatal assume um papel negativo quando propende a estabilizar o crescimento do sistema econômico, pois se orienta a evitar a gangrena do sistema, neste momento a política não visa uma realização de fins práticos, mas sim, a resolução de questões técnicas.

O Estado deve ser tomado analiticamente enquanto uma forma-conteúdo (SANTOS, 2008 [1996]), que na sua essência é responsável pela ação mediadora dos conflitos e contradições arrolados no bojo das classes e grupos sociais, e até mesmo, entre indivíduos, se comportando com um ente terceiro da relação capital-trabalho (MASCARO, 2013). Mas, não podemos esquecer que o próprio Estado assume diversas formas e funções no devenir do processo histórico, por conseguinte, devemos tomá-lo também enquanto conjuntura, melhor dizendo, deve-se ressaltar suas qualidades e características atuais e suas distintas formas de aparecimento no espaço e no tempo, ressaltando suas especificidades históricas e suas formas estruturais, continuações e rupturas.

O Estado deve ser tomado em situação, observando-se a estrutura - o que é contínuo - "daquilo que se mantém de fato, para lá das tempestades do tempo" (BRAUDEL, 1972, p.123) e o que é dado pelo contexto, pela situação econômica, social, cultural e geográfica, destarte, a análise do Estado não deve ser dissociada do tempo histórico, sendo assim, a análise, necessariamente, parte de um lado, através do tempo longo e por outro lado, através do tempo curto - não podemos confundir o tempo curto com o efêmero, com o tempo do cotidiano - esse seria o tempo da situação geográfica ou da conjuntura político-econômica.

Portanto, o presente artigo visa articular um conjunto de ações estatais para transporte e logística, realizadas por meio do PAC, na construção da situação geográfica do território do Rio Grande do Norte. Partimos desse pressuposto analítico para a construção metodológica.

\section{Compreendendo a logística e a fluidez territorial}

Milton Santos (2008 [1996]) concebe o espaço como um conjunto de materialidades animadas por ordens e fluxos, agindo contraditória $\mathrm{e}$ indissociavelmente. Essa teoria tenta abarcar a totalidade dos fenômenos espaciais, concebendo inseparavelmente materialidade e ação.

$\mathrm{O}$ atual período, caracterizado pelo meio técnico-científico-informacional (SANTOS, 2008 [1994]), dissipa por todo planeta lógicas hegemônicas, aquelas de ordem estritamente das empresas, das agências de financiamento global, dos meios de comunicação de massa, etc. Essas lógicas criam e disseminam ideologias, como a da competitividade. A ideologia como assevera Santos (2008, p.126 [1996]) “está na estrutura do mundo e também nas coisas. Ela é um fator constituinte da história do presente". Como fica evidente, a ideologia hoje é um dado concreto, não está pautada apenas no discurso, constitui-se como um elemento que se cristaliza nos objetos e nas ações.

São os objetos e as ações que constituem o espaço geográfico, mas o espaço "não é apenas um receptáculo da história, mas uma condição de sua realização. Essa dialética concreta também inclui, em nossos dias, a ideologia e os símbolos" 
(SANTOS, 2008, p.126 [1996]). Desta forma, no atual estágio de desenvolvimento da história algumas ideologias fundamentam a ação dos indivíduos, além dos "objetos que já nascem como ideologia e como realidade ao mesmo tempo" (p.127).

Algumas ideologias são centrais para o entendimento da realidade, como por exemplo, a da competitividade e a da velocidade. Ambas, frutos da intensificação do processo de racionalização econômica, em que o lucro se torna um objetivo em si. A ideologia da velocidade nos autoriza falar do imperativo da fluidez, baseado "nas redes técnicas, que são um dos suportes da competitividade. Daí a busca voraz de ainda mais fluidez, levando à procura de novas técnicas, ainda mais eficazes. A fluidez é, ao mesmo tempo, uma causa, uma condição e um resultado" (SANTOS, 2008, p.274 [1996]). Porém, a fluidez não é um dado estritamente técnico, ela abarca também as normas, isto é, a política.

Esse espaço racionalizado que é instituído pela prática de mercado, exige formas cada vez mais específicas, por isso da fabricação de sistemas de engenharia criados com intencionalidades privativas, tendentes a cumprir ordens hierarquizadas, que escapam das dimensões do lugar. Essa racionalidade dos/nos objetos também é atravessada nos fluxos; essa relação dialética entre fixo e fluxo é percebida na logística. Nela que a racionalidade dos fixos geográficos e dos fluxos se entrecruza. A logística é uma prática estratégica que visa diminuir a incerteza na armazenagem, nos transportes e na distribuição de coisas; o risco tende a ser eliminado, ou melhor, atenuado, proporcionando maior eficiência e eficácia nos resultados obtidos.

A racionalidade do espaço só foi possível através da densidade técnica, sobretudo das técnicas informacionais, além da generalização do uso da informação. A informação passa a ser o elementochave para o funcionamento eficiente das redes e dos objetos, por isso, a logística ganha destaque nesse período. "Nas condições atuais, o uso mais adequado no território pelos agentes hegemônicos depende largamente desse fator informação, que é uma consequência do nível técnico do equipamento" (SANTOS, 2008, p.298 [1996]).

O que nos permite falar hoje de logística é a banalização do uso da informação, que se constitui enquanto uma informação estratégica, gerada para e a partir das empresas. Arbache et. al. (2011, p.21) diz que a logística

envolve, cada vez em maior grau de importância, a gestão das muitas informações relevantes ao processo de planejamento, execução e controle de fluxo e armazenagem de produtos, além de todos os serviços associados. Assim, gerir informações sobre demanda de clientes, controlar o atendimento de pedidos e manter o rastreamento das entregas sendo realizadas e dos correspondentes pagamentos são atribuições da logística (...).

Por sua vez, Castillo (2007) compreende a logística como uma circulação corporativa, possuindo dimensões infraestruturais, institucionais e estratégicas, que nos permite pensar a logística multidimensionalmente, não a encarando apenas enquanto prática do campo da administração, possibilitando analisar a logística do ponto de vista geográfico, uma vez que a dimensão espacial é inquestionável no processo de produção, circulação, distribuição e consumo.

Para Silva Junior a logística se constituiu enquanto um instrumento para o capital, que utiliza as rugosidades do território em seu benefício, na qual, busca "desobstruir as barreiras territoriais a partir das técnicas e das normas" (2009, p.1). Para o mesmo autor, o capital "encontra na facilidade da circulação proporcionada pelo constante crescimento do meio técnico e da estrutura fixa do território, a base para sua reprodução. Desta maneira, a maior circulação e fluidez são causas e consequências do maior dinamismo e mobilidade do capital" (SILVA JUNIOR, 2002, p.30).

Harvey nos alerta que a redução do tempo de circulação e seu custo são fatores primordiais para a acumulação capitalista. Harvey nos lembra, ainda, de que "ao longo da história do capitalismo muito esforço tem sido posto (...) na redução do atrito de distâncias e dos obstáculos à circulação" (HARVEY, 2011, p.43). Essa tendência geral para a redução das barreiras e obstáculos espaciais que interferem 
diretamente na circulação é um dado intrínseco da evolução técnica, que proporciona a adição de novos objetos geográficos ao território e o melhor uso dos já existentes.

Portanto, compreendemos que a logística é uma síntese entre o imperativo da competitividade e o imperativo da fluidez. É uma prática organizacional que pretende a máxima eficiência e racionalidade para a circulação, armazenagem e distribuição. Essa prática organizacional pretende superar os obstáculos e rugosidades do espaço geográfico, além de tornar ágil o "desembaraço burocrático", seu objetivo é tornar o território uma superfície lisa, plana, um palco à fluidez.

No caso do Brasil, em razão da inflexão liberal na década de 1990 (MANCUSO; OLIVEIRA, 2006), com suas consequentes reformas pró-mercado, resultaram na abertura comercial para "dentro" e para "fora", reestruturando a economia e o território brasileiro. Do aumento da concorrência interna e externa, diversos eventos foram resultantes, como a concentração de capital, graças às fusões, aquisições e falências de empresas de origem nacional, a entrada no mercado nacional de empresas estrangeiras etc. As que resistiram a esse processo passaram a adotar técnicas cada vez mais avançadas, buscando a redução de custos operacionais e maior racionalização das suas atividades.

Assim, a logística no âmbito corporativo ou empresarial, absorveu os paradigmas da globalização e da concorrência em nível global, adotando sistemas flexíveis de produção, racionalizando o tempo e os custos que envolvem todo o processo produtivo. Essa perspectiva da logística tem por objetivo:

planejar alternativas, bem como buscar a redução de custos provocados por gargalos físicos, ineficiências operacionais, obstáculos institucionais, legais e burocráticos em cada uma das etapas de escoamento e de distribuição. Essas etapas vão desde a coleta na origem, estocagem, escoamento e distribuição no destino até o apoio de sistemas de comunicação e de informática nos diversos estágios de deslocamento das cargas. As infraestruturas de transporte, em seus diversos modais, constituem o principal suporte para as atividades relacionadas com a logística (BARAT, 2011, p.218).

Desse contexto de reestruturação da economia nacional e consolidação do meio técnicocientifico-informacional (SANTOS, 2008 [1994]), a logística ganha relevância e passa a ser elemento central das estratégias corporativas (BARAT, 2009). Em interessante diagnóstico, Barat (2009) nos mostra como cresceram de forma vertiginosa os serviços logísticos no Brasil. De acordo com o autor, em 1997 a receita do setor era da ordem de R\$ 1 bilhão, atuando no mercado havia menos de 35 empresas. Comparando com um período de dez anos posteriores, o segmento ampliou seu faturamento para cerca de R $\$ 20$ bilhões, com mais de 120 empresas prestadoras de serviços, muitas delas transnacionais. Além da organização intrafirma, a logística ganha destaque para a redução dos custos de circulação e consequente aumento da competitividade sistêmica, por conseguinte, a demanda por normas e sistemas de engenharia passa a ser o clímax das reivindicações corporativas.

\section{O Programa de Aceleração do Crescimento (PAC): algumas palavras}

A partir do enfoque situacional, observamos que o PAC compreende um encadeamento de eventos complexos, que envolvem diversos elementos de política econômica e social. Criado em 2007, o PAC1 foi dividido em três grandes eixos, Logística, Energética e Social e Urbana. Já o PAC2, lançado em 2011, foi dividido em seis eixos temáticos, Transportes, Energia, Cidade Melhor, Comunidade Cidadã, Minha Casa, Minha Vida e Água e Luz para Todos. Em razão do recorte temático, restringimos a análise do PAC1 e 2 apenas aos investimentos em sistemas de engenharia de transporte e logística.

Com o lançamento do PAC, há uma nítida tentativa de criar um ambiente favorável ao "desenvolvimento" do país, sobretudo, com a criação de macrossistemas de engenharia destinados à estruturação e modernização do território, para tornálo atrativo aos investimentos privados. Esse conjunto 
de novos sistemas de engenharia implica em uma nova organização do território. A configuração territorial criada a partir desses implementos possibilita aos agentes hegemônicos obter maior fluidez, tornandoos aptos a competir no mercado globalizado.

Dentre as principais ações institucionais do PAC estão algumas medidas que visam criar um ambiente favorável ao investimento público e à captação de recursos privados com fins produtivos. $\mathrm{O}$ artigo $1^{\circ}$ do decreto que institui o Programa dispõe sobre os objetivos: "constituído de medidas de estímulo ao investimento privado, ampliação dos investimentos públicos em infraestrutura e voltadas à melhoria da qualidade do gasto público e ao controle da expansão dos gastos correntes no âmbito da Administração Pública Federal” (BRASIL, 2007).

[o] PAC, que conjugou diversas medidas necessárias à consecução das metas estabelecidas para além da garantia do orçamento. O PAC promoveu alterações na legislação tributária; instituiu medidas de estímulo ao crédito e ao financiamento; fortaleceu a capacidade institucional dos órgãos; induziu a organização das administrações públicas subnacionais; e removeu obstáculos burocráticos, normativos, administrativos, jurídicos e legislativos, que criavam restrições à execução (BRASIL Plano Plurianual 2012-2015, 2011, p.113).

Desta forma, percebe-se a modificação da atuação do Estado em relação ao que fora realizado na década de 1990, sob a égide da ideologia neoliberal, sobretudo no que concerne à intervenção estatal no âmbito da economia e do planejamento. As ações ensejadas pelo PAC trazem em sua essência a presença do Estado na regulação, promoção e execução de ações de grande impacto territorial. Outro dado característico da conjuntura diz respeito à retomada do papel de planejador do território pelo Estado brasileiro. Tal modelo é identificado por alguns como social-desenvolvimentista (POCHMANN, 2010) e por outros como neodesenvolvimentista (BOITO \& BERRINGER, 2013).

Além dessa lógica imbricada ao PAC, outra se articula diretamente àquela, isto é, a inclusão de um grande número de brasileiros ao consumo de massa, inseridos através dos programas sociais de transferência de renda, como também a partir da capilarização dos serviços bancários e do acesso ao crédito por parte dessa população, colocandoos no circuito dos bancos; esse processo leva ao que se denomina como "creditização do território" (CONTEL, 2009; SILVEIRA, 2009).

Muito além do PAC, houve no Brasil, posterior à fase neoliberal latente, uma modificação do projeto político. Por ser o primeiro partido de centro-esquerda a assumir o governo do executivo nacional, o Partido dos Trabalhadores - PT modificou seu projeto de poder original, mais crítico à realidade socioeconômica brasileira, para uma visão realista da conjuntura político-econômica nacional, mas sem abrir mão de uma postura proativa na atuação interna e externa, como por exemplo, na busca por maior difusão de parcerias econômicas e sociais, além da ampliação dos acordos Sul-Sul (FIORI, 2013), bem como houve a adoção do "globalismo" (PINHEIRO, 2010) como paradigma da política externa brasileira, ou seja, busca-se maior independência frente aos EUA e à União Europeia.

Existem diversas críticas a respeito do PAC, pois o consideram apenas como uma norma que ordena os investimentos já previstos. Conforme nos indica Passarinho (PASSARINHO, 2007, p.4) “Trata-se de verbas já previstas de aplicação através dos Orçamentos Fiscal, da Seguridade Social ou das Estatais, ou de recursos a serem oferecidos por mecanismos de estímulo ao crédito e ao financiamento". Por isso, o PAC não trouxe grandes novidades para o planejamento, o único elemento novo citado por Passarinho (2007), diz respeito ao aumento da cota percentual do Produto Interno Bruto (PIB) destinado ao investimento em infraestrutura, passando de $0,2 \%$ para $0,5 \%$, ou seja, um incremento no poder de investimento em infraestruturas.

Para Sampaio Jr. (2007) o PAC se constitui como uma repetição e consolidação do modo de acumulação neoliberal-periférico, iniciado com o Governo Collor de Mello. Para esse autor, o PAC não seria capaz de garantir ao mínimo as infraestruturas necessárias para evitar os ciclos de decréscimo da 
economia. Além disso, o PAC busca na iniciativa privada os investimentos que o Estado não está apto a realizar, acentuando a "privatização da economia, estimulando as Parcerias Público-Privadas e as Sociedades de Propósitos Especiais; transfere, por diferentes mecanismos, grandes volumes de recursos fiscais e para-fiscais para a iniciativa privada" (SAMPAIO JR, 2007, p.5-6). Para finalizar sua análise, Sampaio Jr. afiança que o PAC busca algo impossível: "superar a estagnação aprofundando o padrão de acumulação responsável pela paralisia da economia brasileira. Para tanto, recomenda mais negócios para o capital, mais arrocho para os trabalhadores" (SAMPAIO JR, 2007, p.10).

A partir dessas análises, acreditamos que apesar de não ser um programa com grandes novidades institucionais, o PAC tende a criar novas qualidades e quantidades no território brasileiro, aprofundando os nexos do meio técnico-científico-informacional, e consequentemente a tecnoesfera que o sustenta - esta seria o mundo dos objetos técnicos, são as próteses adicionadas ao território (SANTOS, [1993] 2009, p.50)-, e a psicoesfera que margeia e expande o sentimento de desenvolvimento presente no seu discurso - a psicoesfera é o mundo das ideias, das crenças, dos valores, das ideologias, do imaginário (SANTOS, 2009 [1993], p.50).

$\mathrm{O}$ PAC permite o planejamento visando à integração dos sistemas de movimento da totalidade do território brasileiro, assim, podemos falar de intermodalidade dos sistemas de movimento. Essa integração entre os sistemas ferroviários, rodoviário, dutoviário, aeroviário, marítimo (de cabotagem e de longo curso) e fluvial é um dos elementos que aprofundam a fluidez territorial, sobretudo para a ampliação da competitividade sistêmica da economia nacional no cenário internacional. Não podemos negligenciar que tal integração apenas engatinha no Brasil, distante de se tornar um dado universalconcreto no território brasileiro.

A fluidez territorial, além da materialidade requer outro elemento, as normas (ARROYO, 2005). Sem elas não existe regulação para o uso de cada objeto e do conjunto dos sistemas de engenharia. A combinação entre os sistemas técnicos e as normas associadas, implica em diferentes coeficientes de fluidez para os agentes que se utilizam desses sistemas. Essa forma híbrida de existir entre materialidade e normas é quem possibilita-nos falar de fluidez potencial, que só se efetiva e ganha existência concreta através do uso. Os atores envolvidos nesse processo se utilizam de forma variada de cada sistema de engenharia e do seu conjunto (SANTOS e SILVEIRA, 2011 [2001]), o que resulta em diferentes capacidades de uso.

Cada objeto é disposto segundo uma intencionalidade. As intencionalidades não se restringem apenas à fabricação do objeto. Vão além: são responsáveis pela localização, que segue uma lógica; são intencionalidades precisas e com uma racionalidade superior. É esse o objetivo do pesquisador, compreender a coerência da "arrumação das coisas" (GOMES, 1997) em vigência e compreender a disposição de cada objeto e do conjunto das formas no território e as dinâmicas dela resultantes.

Para isso, cada objeto é qualificado de uma forma; cada objeto geográfico é único. Assim, os objetos possuem atributos diferenciados e também usos diferenciados, uma vez que a especificidade do uso corresponde ao lugar onde está instalado e do arranjo a que está submetido, com relações de complementaridade e conflito. Essa localização intencional dos objetos geográficos dentro do PAC é derivada de um macroplanejamento com vistas à integração intermodal dos sistemas de transporte no território brasileiro, mas que atendem apenas algumas intencionalidades.

\section{Os investimentos em transporte e logística no Rio Grande do Norte}

No que diz respeito aos investimentos do PAC no Rio Grande do Norte, primeiramente se faz necessário contextualizar os investimentos realizados na Região Nordeste e no Brasil, para se estabelecer critérios comparativos que facilitem a visualização de tais ações (ver Tabela 1). 
Tabela 01- Investimentos em empreendimentos do Programa de Aceleração do Crescimento

\begin{tabular}{|c|c|c|c|c|}
\hline & $\begin{array}{c}\text { PAC 1 } \\
2007-2010-\mathrm{R} \$ \text { bi }\end{array}$ & $\begin{array}{c}\text { Logística } \\
\mathrm{R} \$ \text { bi }\end{array}$ & $\begin{array}{c}\text { PAC 2 2011- } \\
2014-\mathrm{R} \$ \text { bi }\end{array}$ & $\begin{array}{c}\text { Logística } \\
\mathrm{R} \$ \text { bi }\end{array}$ \\
\hline Brasil & 619 & $65.4^{*}$ & $1.06^{* *}$ & $66.9^{*}$ \\
\hline Nordeste & 156.6 & $16.15^{* * *}$ & 240 & $11.67^{* * *}$ \\
\hline Rio Grande do Norte & 12.8 & $974,4^{* * * *}$ & 24.8 & $1.58^{* * *}$ \\
\hline
\end{tabular}

Fonte: COMITÊ GESTOR DO PAC. Balanço de 4 anos - 2007-2010. 2010; Balanço 4 anos, 11 Balanço, 2011-2014. 2014.

Elaboração do autor.

* ações concluídas no período 2007-2010 e 2011-2014, respectivamente.

** R $\$$ trilhões.

*** investimentos estaduais exclusivos, não incluem os investimentos de caráter regional.

$* * * * \mathrm{R} \$$ milhões.

Como se pode notar na Tabela 1, a destinação de recursos para região Nordeste é significativa para transporte e logística. Podemos destacar alguns investimentos realizados na região, entre os quais: a duplicação da BR-101, trechos entre os estados do Rio Grande do Norte e Sergipe; adequação entre o acesso ao Porto de Pecém (CE) e o município de Sobral (CE), trecho de $194 \mathrm{~km}$. Outras ações de importante vulto foram realizadas no modal portuário, a destacar: dragagem de aprofundamento em alguns portos, Natal (RN), Recife (PE), Aratu (BA) e Salvador (BA), além da construção do Berço 108 no Porto de Itaqui (MA) e do acesso rodoviário ao Porto de Suape (PE). Ainda no modal portuário foram construídos terminais de passageiros nos portos de Natal, Recife e Fortaleza. No âmbito do modal ferroviário, destaca-se o projeto da Ferrovia Transnordestina. No caso dos investimentos em aeroportos se destacam a construção da nova torre de controle e do pátio de aeronaves no Aeroporto de Salvador/BA; no Aeroporto de Fortaleza foi construído o terminal de cargas e torre de controle; no Aeroporto de João Pessoa foi realizada reforma e ampliação do terminal de passageiros e reforço da pista de pouso, entre outras ações.

No caso do Rio Grande do Norte, os novos objetos técnicos atendem ao critério de consolidação dos circuitos espaciais produtivos (SANTOS, 2012
[1988]) já existentes, como o caso da produção salineira e da fruticultura irrigada, ou ao benefício de atividades já consolidadas, como o turismo. Vejamos agora alguns investimentos do PAC por modal no estado potiguar (ver Figura 01). 
Figura 01 - Investimentos do PAC em Infraestrutura de Transporte no Rio Grande do Norte

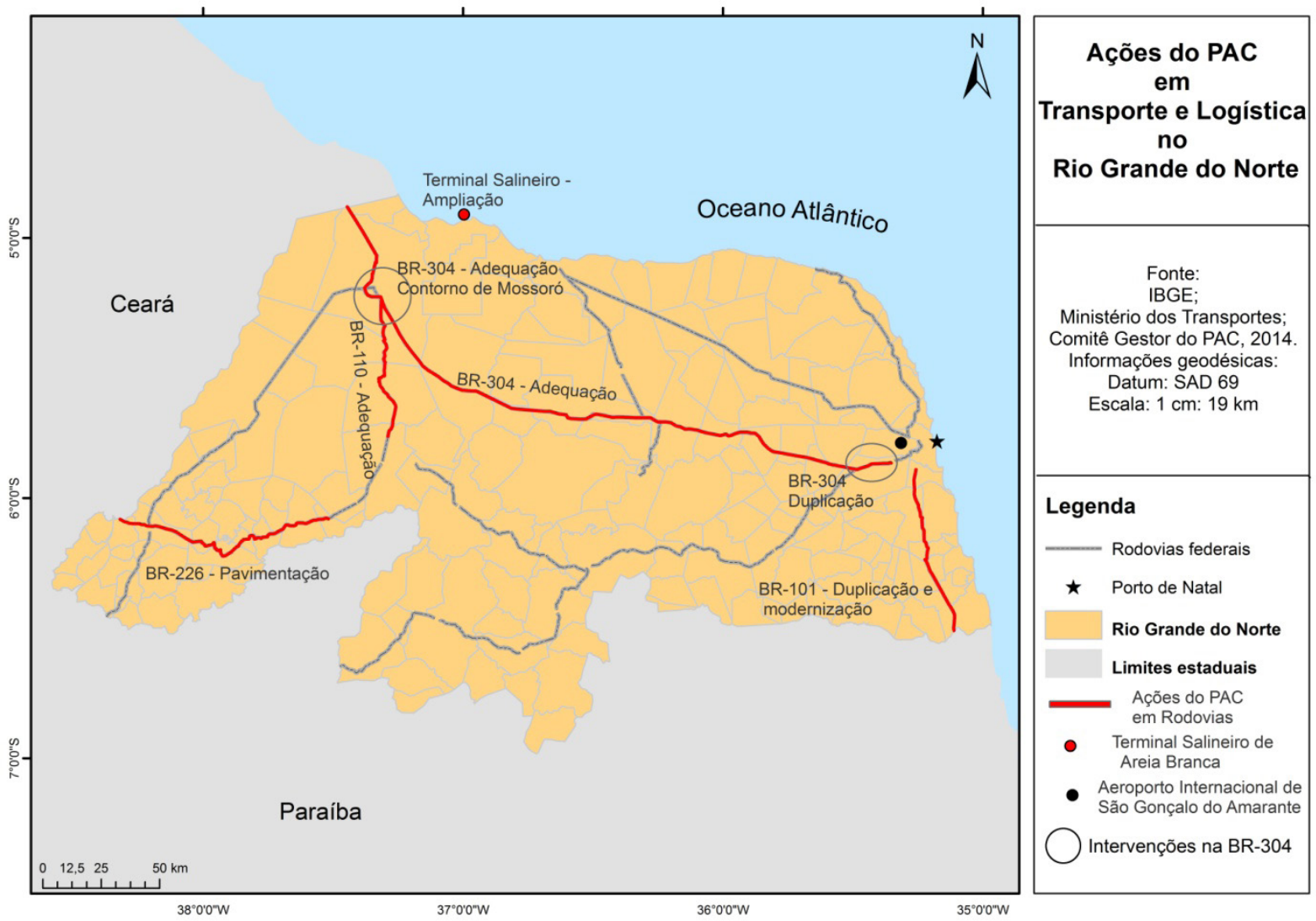

Fonte: COMITÊ GESTOR DO PAC, 2012, org. do autor.

A estratégia para ampliar a infraestrutura logística existente no estado do Rio Grande do Norte, busca, sobretudo, majorar e adequar a infraestrutura preexistente, de modo que beneficie os circuitos espaciais de produção já estabelecidos. Dentre as estratégias busca-se melhorar as condições de interligação do estado potiguar com os demais estados do Nordeste, via a BR-101. Esse projeto se enquadra em outro mais amplo, que se estende do estado do Rio Grande do Sul até o estado potiguar, contando com obras de duplicação, trechos destinados à concessão (no Espírito Santo e Rio de Janeiro) e diversas adequações. No território norterio-grandense foram realizadas obras de duplicação e modernização do trecho que faz divisa com a Paraíba (iniciada no município de Arês), e do trecho que liga Natal à Arês, embora esteja prevista a realização de obras complementares.

Com a pavimentação da BR-226 e da BR-
110, da adequação do contorno de Mossoró na BR-304 (contorno da área mais urbanizada) e da duplicação do trecho da BR-304 (a obra encontrase paralisada) que vai de Macaíba à Natal, visa-se melhorar as condições de escoamento da produção regional, assim como, melhorar as condições de trafegabilidade e segurança dos usuários. No caso da pavimentação de trechos da BR-110 e da BR-226, a ação possui forte caráter regional/local, uma vez que permite melhorar a integração entre os municípios cortados pela rodovia (BR-226), entre eles: Almino Afonso, Antônio Martins, Encanto, Frutuoso Gomes, Patu, Pau dos Ferros, Serrinha dos Pitos. Vale lembrar que o município de Pau dos Ferros desempenha papel central na dinâmica da região do Alto Oeste, constituindo-se como um importante centro comercial. É uma ação que além de ampliar as condições de escoamento da produção regional, favorecerá o fortalecimento da rede urbana local. 
No caso específico da duplicação da BR-304 entre o município de Macaíba (Região Metropolitana de Natal - RMN) e Natal, faz-se necessário devido à concentração de serviços de diversas ordens em Natal, o que acarreta numa grande procura, gerando um fluxo contínuo para a capital estadual. Essa rodovia é um dos principais eixos de circulação do $\mathrm{RN}$, pois liga as duas principais cidades do estado, Natal e Mossoró, formando o eixo Natal-Mossoró-Fortaleza, já que a rodovia liga-se à Russas, no estado do Ceará, entroncando-se à BR-116 para ligar-se à Fortaleza. A rodovia, no trecho no município de Macaíba, recebe o fluxo da BR-226, rodovia responsável por conectar a Região Metropolitana de Natal a Região Seridó, onde se localizam dois importes municípios, Currais Novos e Caicó, responsáveis pela estruturação da rede urbana daquela região. A BR-304 na altura do município de Parnamirim (RMN) entronca-se à BR101 - responsável por fazer a conexão regional entre diversas capitais estaduais, como João Pessoa/PB, Recife/PE, Maceió/AL, Aracaju/SE, além de ligarse à região Sudeste e Sul. Portanto, a rodovia possui caráter estratégico na circulação de bens e pessoas no estado do Rio Grande do Norte.

O Porto de Natal conta com ações de dragagem, visando melhorar o acesso ao porto, com a ampliação do seu calado, o que implicará no recebimento de navios com maior capacidade de carga, assim como a possibilidade de receber navios turísticos. Há também o projeto, ainda não concretizado, de construção de um novo berço de atracação, que terá 220 metros de comprimento e incluirá o píer de combustíveis da Petrobrás, o Píer das Dunas, que dispõe de equipamentos necessários para manuseios de combustíveis. Além do novo berço, o Porto de Natal ganhará uma retroárea de $8.000 \mathrm{~m}^{2}$, que permitirá a atender as exigências e demanda dos exportadores de combustíveis renováveis tais como: álcool, óleos vegetais e biodiesel, o que justificaria a implantação dos tanques com um volume total de $17.000 \mathrm{~m}^{3}$ (CODERN, 2010b).

No caso do empreendimento que envolve a construção do berço $\mathrm{n}^{\circ}$ 04, na direção norte e ampliação da retroárea em $8.000 \mathrm{~m}^{2}$, evitará que ocorra a impossibilidade de recepção de embarcações mercantes ou de cruzeiro e as indesejáveis sobreestadias ocasionadas pela demora em atracar no aguardo de espaço no cais. O Porto de Natal apresenta crescimento nos últimos anos na movimentação geral de cargas, tanto embarque quanto desembarque, o que justificaria a construção do novo berço (Figura 02).

Figura 02 - Histórico da Movimentação Geral de Carga no Porto de Natal - 2007-2013

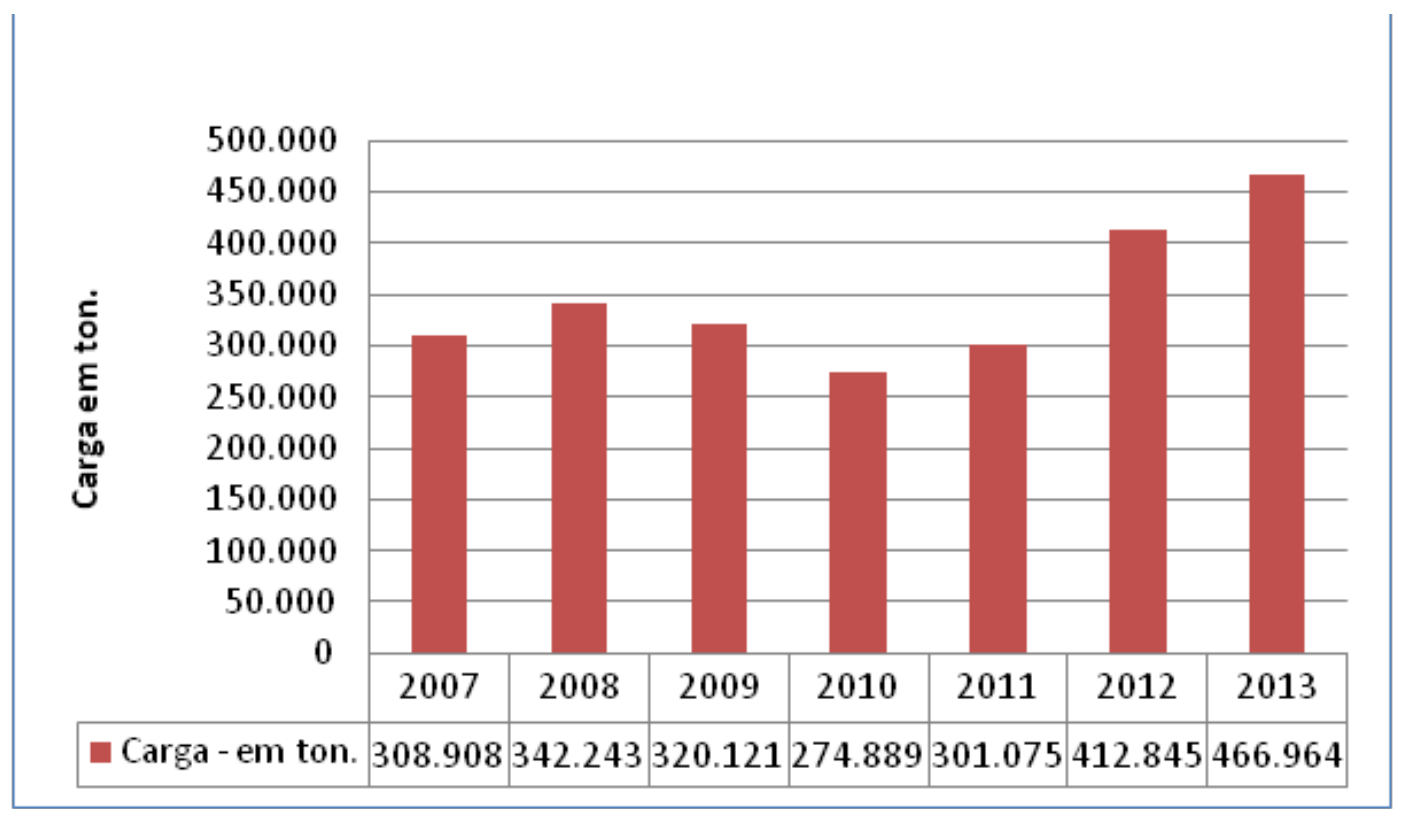

Fonte: CODERN (2013); Org. do Autor. 
O Porto de Natal se constitui enquanto um porto complementar aos portos pernambucanos e cearenses; sua existência, a princípio, não é compreendida pela autonomia que desempenha para o território e comércio potiguar, mas se enquadra num campo mais amplo de relações, que se estende pelo Nordeste, e podendo ampliar ainda mais esse nexo explicativo para situá-lo dentro do contexto do território nacional. A função complementar é evidente quando se analisa o escoamento da produção potiguar para o mercado exterior pelo modal portuário, sendo o Porto de Pecém (CE) a principal porta de saída, concentrando $32,6 \%$ do valor exportado em todo o RN, no ano de 2013. O porto cearense é seguido pelo Porto de Natal, com 25,2\% do valor exportado; em terceiro fica o Porto de Fortaleza (CE), com 7,9\%; seguido pelo Porto de Suape (PE), com $6,9 \%$ do valor exportado. Na lista ainda entram os Portos de Santos (2,6\%), Areia Branca (Terminal Salineiro), com 2,5\%, o Porto de Recife (PE), com 2,1\%, São Francisco do Sul (SC), com 1,9\%, Cabedelo (PB), com 1,6\%, Rio Grande (RS), com 1,5\% (FIERNCIN, 2013).

Os Portos cearenses de Pecém e Fortaleza concentraram juntos, no ano de 2013, 47,2\% do valor transportado do Rio Grande do Norte pelo modal portuário com destino a exportação, o que representa $40,5 \%$ do valor total das exportações potiguares. Os principais produtos de origem potiguar exportados pelos portos cearenses são, sobretudo, frutas, castanhas de caju, balas, lagostas, produtos animais, tecidos de algodão e cera de carnaúba. Esses portos dividem com o Porto de Natal a exportação de frutas tropicais (FIERN-CIN, 2013).

A atividade turística também foi beneficiada através da construção do Aeroporto Internacional de São Gonçalo do Amarante e com o Terminal de Passageiros do Porto de Natal. O Aeroporto Internacional de São Gonçalo do Amarante (Aeroporto Internacional Governador Aloízio Alves) foi o primeiro aeroporto nacional a entrar no processo de concessão - construção parcial, manutenção e exploração. A concessão ocorreu através de leilão (realizado pela BM\&FBOVESPA S.A. - Bolsa de Valores, Mercadorias e Futuros), avaliada pelo critério de maior valor de outorga. O Consórcio Inframerica, formado pelas empresas Infravix Participações S/A e Corporación América S/A, foi o vencedor do certame, outorgado em 11 de outubro de 2011, com prazo de validade da concessão de 28 anos, através do lance de R $\$ 170$ milhões, com previsão de investimento de R \$ 650 milhões até o final do período (ANAC, 2011; COMITÊ GESTOR DO PAC, 2012).

Já atividade salineira foi contemplada com ações de repotencialização e ampliação do Terminal Salineiro de Areia Branca. Esse conjunto de reformas tornará mais seguro e ágil o funcionamento do Terminal Salineiro, acarretando em mais velocidade no descarregamento das barcaças e carregamento dos navios, desta forma, acompanha o crescimento do mercado de consumo, sobretudo, das indústrias que utilizam grandes volumes de sal nos seus processos produtivos, como a indústria química, refino de petróleo, produtos minerais não metálicos, indústria do cloro, soda, papel e gráfica etc., além de garantir a possibilidade de lidar com navios maiores e com maior movimentação de carga (CODERN, 2010a).

O estado do Rio Grande do Norte não foi contemplado com nenhum projeto de investimento para o modal ferroviário no PAC, inclusive ficando fora do percurso e de ligações com a Ferrovia Nova Transnordestina, que tem como ponto inicial o município de Eliseu Martins/PI, passando pelos estados de Pernambuco e Ceará. No Ceará a ferrovia bifurca-se, em direção ao porto cearense de Pecém e em direção ao Porto de Suape (PE), formando um grande $\mathrm{Y}$, com $1.728 \mathrm{~km}$ de extensão. A conexão aos dois portos é explicada por ambos possuírem profundidade suficiente para receberem navios do tipo capesize, de capacidade que vai de 80 a 199 mil toneladas (Transnordestina Logística S. A., 2013).

O foco da Nova Transnordestina serão os circuitos espaciais de produção ligados ao agronegócio e a indústria mineral. Os principais produtos que serão transportados pelo novo trajeto, de acordo com a empresa operadora, a saber: álcool, algodão (caroço e pluma), argila, arroz, biodiesel, cal, cimento, contêineres, farelo de soja, fertilizantes, gasolina, gesso, gipsita, milho, óleo de soja e minério de ferro (VENCOVSKY, 2011).

Dentro do grande $\mathrm{Y}$ formado pelo traçado da ferrovia, o Rio Grande do Norte foi isolado, sem 
conexões ferroviárias. Esse é um bom exemplo de como o território brasileiro é organizado, enquanto alguns subespaços são viabilizados do ponto de vista econômico, outros são esquecidos. Essa viabilização decorre da escolha de empresas privadas, como a Transnordestina Logística S/A., como provém do próprio Estado, quando decide quais projetos serão financiados com recursos públicos. Lembramos que hoje, no caso do Rio Grande do Norte, a malha ferroviária foi esquecida, envelhecida, deteriorada, e em alguns casos completamente destruída - como no trecho entre Mossoró e Sousa, na Paraíba, em que os trilhos foram retirados do traçado - o que restou foram as antigas estações, como no caso da de Mossoró, transformada em espaço cultural. Hoje, o Rio Grande do Norte conta apenas com um pequeno trecho ferroviário em operação, dividido em duas linhas, ambas na RMN, a Linha Norte, Natal/CearáMirim (38,5 km) e a Linha Sul, Natal/Parnamirim $(17,7 \mathrm{~km})$, controladas pela Companhia Brasileira de Trens Urbanos - CBTU, que transporta em média nove mil passageiros por dia.

Com a inexistência do transporte ferroviário de carga, o Rio Grande do Norte fica restrito ao uso do modal rodoviário para transportar a produção para os portos ou para o mercado interno. O modal rodoviário é caro, com altos custos de manutenção, tanto da frota, como das vias, com emissões elevadas de gases poluentes e fuligem. Por outro lado, as ferrovias possuem altos custos de implantação, mas apresentam maior capacidade de transporte de carga.

Os investimentos no modal ferroviário atendem a interesses de alguns circuitos espaciais de produção, como no caso dos investimentos na Região Centro-Oeste, que visam atender o escoamento da produção de grãos (VENCOVSKY, 2011). Na escolha dos projetos prioritários a modificação da matriz de transporte é suplantada pela preponderância da viabilidade econômica, que em muitos casos existe, porém não oferecendo uma taxa de retorno elevada, com lucros em curto e médio prazo. Como se diz: existe viabilidade econômica, mas inexiste viabilidade financeira.

Por requerer alto investimento inicial, as ferrovias em muitos casos não atraem a atenção do setor privado, ficando sob aresponsabilidade da União, que por falta de recursos, elege uma série de projetos prioritários para serem executados. Vale salientar que as ferrovias só justificam o investimento se houver produção em grande escala, longas distâncias para movimentação de carga, entre $500 \mathrm{~km} \mathrm{e} 1200 \mathrm{~km}$ (CAIXETA-FILHO, 2001). Porém, mesmo com baixa lucratividade, a existência de ferrovias pode ser pensada como um elemento a beneficiar a atração de novos investimentos, funcionando como economias externas.

Por isso, o modal rodoviário ainda é o mais democrático em termos de uso, pois todos os agentes podem utilizá-lo, sejam do circuito superior da economia ou do circuito inferior (SANTOS, 2008 [1979]), não importando a distância, o tamanho e tipo da carga, e o frete retorno, embora seja mais poluente.

É comum a literatura estrangeira propor por exemplo o uso do modo ferroviário para percursos superiores a $500 \mathrm{~km}$. Além de estabelecer, também, o uso de frota rodoviária própria para distâncias menores. A estrutura brasileira, no entanto, é sensivelmente diferente e não adianta, por exemplo, propor ao usuário que utilize a ferrovia a partir de determinada distância, quando se sabe que a rede ferroviária disponível atinge apenas uma parte do território nacional. Por outro lado, pensar em utilizar a ferrovia para cargas parceladas, embora o frete de transferência possa ser menor, ninguém imagina como viável, tendo em vista todas as despesas para entrega e coleta que devem ser realizadas nas extremidades além de todo o controle que se tornaria necessário para saber se a carga chegou adequadamente e no tempo certo ao destino (GOEBEL, 1996).

Como se pode ver, as ações do PAC destinadas a ampliar a fluidez territorial, buscam esse objetivo através da modificação da configuração territorial com o acréscimo de novos objetos, como no caso do Aeroporto Internacional de São Gonçalo do Amarante, ou a readequação dos objetos preexistes às novas demandas, como por exemplo, a duplicação da BR-101 e a readequação do Terminal Salineiro de 


\section{Areia Branca.}

A logística é assim, elemento central para racionalizar e nortear as ações do Estado para alguns setores; porém, ela ultrapassa o âmbito das empresas, agora, o território é quem se torna competitivo, quanto maior a densidade técnica e infraestrutural, maior é a produtividade espacial (SANTOS, 2008 [1996]).

Os lugares se distinguiram pela diferente capacidade de oferecer rentabilidade aos investimentos. Essa rentabilidade é maior ou menor, em virtude das condições locais de ordem técnica (equipamentos, infraestrutura, acessibilidade) e organizacional (leis locais, impostos, relações trabalhistas, tradição laboral). Essa eficácia mercantil não é um dado absoluto do lugar, mas se refere a um determinado produto e não a um produto qualquer (SANTOS, 2008 [1996], p. 247248).

Esses critérios logísticos são fundamentais para o processo de desenvolvimento e no barateamento dos custos com transportes, assim como favorecem a fragmentação territorial, com o consequente aumento da competição entre os entes federados. É importante ressaltar que no Rio Grande do Norte, os investimentos possuem um duplo caráter, de um lado os investimentos para o grande capital, como a construção de um novo aeroporto, haja vista que o antigo Aeroporto (Aeroporto Internacional Augusto Severo) atendia as necessidades locais; de outro lado, temos investimentos que atendem a integração regional, como a pavimentação de rodovias federais, responsáveis pela circulação regional de bens e pessoas.

\section{CONSIDERAÇÕES FINAIS}

A logística da maneira como é conduzida pelo Programa de Aceleração do Crescimento não difere dos antigos "corredores de exportação". Segundo Ablas, nos anos 80 se convencionou chamar de "corredores de exportação" os eixos de circulação destinados à economia externa, "seriam vias privilegiadas de escoamento da produção na direção dos portos com destino ao exterior" (ABLAS, 2003, p.171).

Essa forma de equacionar o problema do desenvolvimento econômico e social foi proporcionada por uma visão deturpada dos efeitos multiplicadores proporcionados pelos "corredores de exportação", pois eram subsidiados por uma hipótese que "existindo uma via de acesso ao exterior a produção agrícola se implantaria com uma certa facilidade levando à ocupação e ao desenvolvimento do interior", e conclui nosso autor "no entanto, privilegiando o comércio externo, essa proposta caracterizou-se pela pouca contribuição às economias localizadas entre os pontos de origem e destino dos corredores, concentrando-se o crescimento econômico apenas em suas extremidades (...)" (ABLAS, 2003, p.171).

Portanto, as ações para transporte e logística atuais, em parte, repetem o erro dos corredores de exportação, pois criam uma complexa infraestrutura no territorial nacional para atender a demanda de alguns agentes e de alguns circuitos espaciais produtivos, tendo como norte, o mercado externo.

As infraestruturas de transporte não podem se restringir a um elemento a ampliar as relações competitivas dentro do território nacional. As relações impostas através dos transportes devem ser erigidas a partir da complementaridade, o que possibilitaria a construção de um federalismo integrado, a evitar as disputas internas e equilibrando as desigualdades regionais.

O conjunto de ações para transporte e logística remete a um planejamento estratégico, com vistas a equipar o território nacional em médio prazo; embora seja necessário ressaltar que essas ações, em muitos casos, atendem a interesses privados, isto é, respondem às demandas de alguns atores, sobretudo, aqueles que possuem maior poder econômico e, consequentemente, político.

As ações do PAC são resultado do processo de seletividade espacial, no qual cada subespaço é qualificado de acordo com sua capacidade de rentabilizar uma dada produção. Porém, existem empreendimentos que visam à integração regional através de uma melhor circulação de pessoas e mercadorias, como por exemplo, a pavimentação de 
rodovias que conectam municípios do interior do Rio Grande do Norte.

O Rio Grande do Norte é um estado desigualmente composto, no qual coexiste, de um lado, uma estrutura arcaica de produção, e de outro, formas mais dinâmicas. Portanto, essas ações que modernizam a estrutura de transporte, criando novos sistemas de engenharia, convivem com outra estrutura, extremamente inadequada, como são, por exemplo, as rodovias estaduais, responsáveis por fazer a ligação entre diversos municípios do interior, muitas delas não asfaltadas ou em estado precário de conservação.

A fluidez territorial tão buscada no período coevo, não é levada a todas as frações do território, apenas aqueles espaços qualificados como aptos a receberem os novos implementos técnicos. Com o Rio Grande do Norte não é diferente; a lógica que prevalece é aquela na qual as desigualdades são reproduzidas, onde o velho e o novo estão em processo constante de contradição.

\section{REFERÊNCIAS}

ABLAS, L. Os "Estudos dos Eixos" como instrumento de planejamento regional. In: GONÇALVES, M. F.; BRANDÃO, C. A.; GALVÃO, A. C. F. (orgs). Regiões e Cidades, Cidades nas Regiões: o desafio urbanoregional. São Paulo: Editora UNESP: ANPUR, 2003.

ANAC. Agência Nacional de Aviação Civil. Decisão $n^{\circ} 111$, de 11 de outubro de 2011.

ARBACHE, F. S. [et. al.]. Gestão de logística, distribuição e trade marketing. $4^{\circ}$ ed. Rio de Janeiro: Editora FGV, 2011.

ARROYO, M. Fluidez e porosidade do território brasileiro no contexto da integração continental. In: SILVEIRA, M. L. (org.). Continente em Chamas: globalização e território na América Latina. Tradução Eliana Aguiar. Rio de Janeiro: Civilização Brasileira, p.209-242, 2005.

BARAT, J. Planejamento das Infraestruturas de Logística e Transporte. Radar: Produção, Tecnologia, e Comércio Exterior. DISET/IPEA, 2009.

BARAT, J. Infraestrutura de logística e transporte: análise e perspectivas. In: SILVEIRA, M. R. (org.), Circulação, transporte e logística: diferentes perspectivas. São Paulo: Outras Expressões, 2011, pp.217-26.

BOITO Jr., A; BERRINGER, T. Classes sociais, neodesenvolvimentismo e política externa nos governos Lula e Dilma. Revista de Sociologia e Política, Curitiba, v.21, n.47, p.37-38, set., 2013. DOI: http:// dx.doi.org/10.1590/S0104-44782013000300004

BRASIL. Decreto N ${ }^{\circ} 6.025$, de 22 de Janeiro de 2007. Institui o Programa de Aceleração do Crescimento PAC, o seu Comitê Gestor, e dá outras providências. 2007.

BRASIL. Ministério do Planejamento, Orçamento e Gestão. Secretaria de Planejamento e Investimentos Estratégicos. Plano plurianual 2012-2015: projeto de lei. Brasília: MP, 2011.

BRAUDEL, F. História e Ciências Sociais. 3. ed. Lisboa: Editorial Presença, 1972.

CAIXETA-FILHO, J. V. Competitividade do transporte no agribusiness brasileiro. In: CAIXETAFILHO, J.; GAMEIRO, A. H. (Orgs.). Transporte e logística em sistemas agroindustriais. São Paulo: Atlas, 2001

CASTILlO, R. Agronegócio e Logística em Áreas de Cerrado: expressão da agricultura científica Globalizada. Revista da ANPEGE. v. 3, p. 33 - 43, 2007.

CATAIA, M. A. Território político: fundamento e fundação do Estado. Sociedade e Território, Uberlândia, 23 (1), p.115-125, abr., 2011.

CODERN. Companhia Docas do Rio Grande do Norte. Plano de Desenvolvimento e Zoneamento Terminal Salineiro de Areia Branca. Natal, 2010a. 
CODERN. Companhia Docas do Rio Grande do Norte. Plano de Desenvolvimento e Zoneamento do Porto de Natal. Natal, 2010b.

CODERN. Companhia Docas do Rio Grande do Norte. Estatística portuária dos Portos do RN. Histórico da Movimentação Geral de Cargas no Porto de Natal 2007-2013 (em ton.), Dezembro, 2013. Disponível em: $<$ http://codern.com.br/porto-de-natal/estatistica/>. Acesso em: 24 de junho de 2014.

CONTEL, F. B. Espaço Geográfico, Sistema Bancário e a Hipercapilaridade do Crédito no Brasil. CADERNO CRH, Salvador, v. 22, n. 55, p. 119134, Jan./Abr. 2009. DOI: http://dx.doi.org/10.1590/ S0103-49792009000100007

COMITÊ GESTOR DO PAC. Balanço 4 anos - 20072010. 2010.

COMITÊ GESTOR DO PAC. $4^{\circ}$ Balanço do estado do Rio Grande do Norte, jan./abr. de 2012.

COMITÊ GESTOR DO PAC. $10^{\circ}$ Balanço, março/ junho de 2014.

COMITÊ GESTOR DO PAC. Balanço 4 anos, $11^{\circ}$ balanço, 2011-2014. 2014.

FIERN. Federação das Indústrias do Rio Grande do Norte; CIN. Centro Internacional de Negócios. Exportações do RN por modais e locais de embarque 2013 (Fonte: Aliceweb - MDIC/SECEX), 2013. Disponível em: <http://www.fiern.org.br/index.php/ centro-internacional-de-negocios/dados-estatisticoscomercio-exterior>. Acesso: 20 maio de 2014.

FIORI, J. L. O Brasil e seu "entorno estratégico" na primeira década do século XXI. In: SADE, Emir (org.). 10 anos de governos pós-neoliberais no Brasil: Lula e Dilma. São Paulo: Boitempo; Rio de Janeiro: FLACSO Brasil 2013.

GOEBEL, D. Otimização do transporte e estoques na empresa. Estudos em Comércio Exterior, Vol. I n ${ }^{\circ}$ 1 - jul/dez 1996.
GOMES, P. C. da C. Geografia fin-de-siècle: o discurso sobre a ordem do mundo e o fim das ilusões. In: GOMES, P. C. da C.; CASTRO, I. E. de; CORREA, R. L. (Org.). Explorações geográficas. Rio de Janeiro: Bertrand Brasil, 1997, v. 1, p. 13-4.

HABERMAS, J. Técnica e Ciência como "Ideologia". Lisboa: Edições 70, 2011.

HARVEY, D. O Enigma do Capital: e as crises do capitalismo. São Paulo: Boitempo, 2011.

MANCUSO, W. P.; OLIVEIRA, A. J. de. Abertura Econômica, Empresariado e Política: os planos doméstico e internacional. Lua Nova, São Paulo, 69: p.147-172, 2006.

MASCARO, A. L. Estado e Forma Política. São Paulo: Boitempo, 2013.

PASSARINHO, P. Programa de Aceleração do Crescimento - PAC - uma Inflexão da Política Econômica ou Mera Busca de Resultados?, 2007. Disponível em: <http://www.corecon-rj.org.br/ced/ avaliacao_pac_paulo_passarinho.pdf $>$. Acesso em: 28 jun. 2012.

PINHEIRO, L. Política externa brasileira (18892002). 2.ed., Rio de Janeiro: Zahar, 2010.

POCHMANN, M. Desenvolvimento e perspectivas novas para o Brasil. São Paulo: Cortez, 2010.

SAMPAIO JR., P. de A. Notas Sobre o PAC: um passo atrás. Texto da palestra realizada no CORECOM-RJ, em 14 de março de 2007.

SANTOS, M. O Espaço Dividido: os dois circuitos da economia urbana dos países subdesenvolvidos. 2.ed. 1. reimpr. São Paulo: Edusp, 2008 [1979].

SANTOS, M. Metamorfose do Espaço Habitado: fundamentos teóricos e metodológicos da geografia. 6. ed., 1. reimpr., São Paulo: Edusp, 2012 [1988]. 
SANTOS, M. A Urbanização Brasileira. 5. ed., 2. reimpr., São Paulo: Edusp, 2009 [1993].

SANTOS, M. Técnica, Espaço, Tempo: Globalização e Meio Técnico-cientifico-informacional. 5. ed. São Paulo: Edusp, 2008 [1994].

SANTOS, M. A Natureza do Espaço: Técnica e Tempo. Razão e Emoção. 4. ed. São Paulo: Edusp, 2008 [1996].

SANTOS, M.; SILVEIRA, M. L. O Brasil: território e sociedade no início do século XXI. $15^{\mathrm{a}}$ ed., Rio de Janeiro: Record, 2011 [2001].

SILVA JUNIOR, R. F. da. Eliminação de "barreiras": produção de fluidez e circulação no Brasil. Revista Formação - Edição Especial - n.13 v.2. 2002.

SILVA JUNIOR, R. F. da. Normas e dotação de fluidez ao território: os operadores de transporte multimodal no Brasil. In: $12^{\circ}$ Encuentro de Geografos de America Latina: caminando en una America Latina en transformación, 2009, Montevidéu. Anais do $12^{\circ}$ Encuentro de Geografos de America Latina, 2009.

SILVEIRA, M. L. Finanças, Consumo e Circuitos da Economia Urbana na Cidade de São Paulo. CADERNO CRH, Salvador, v. 22, n. 55, p. 65-76, Jan./Abr. 2009. DOI: http://dx.doi.org/10.1590/ S0103-49792009000100004

TRANSNORDESTINA LOGÍSTICA S. A. Relatório da Administração 2013. Disponível em: $<$ http://www. relacoescominvestidores.com.br/csn/>. Acesso: $25 \mathrm{de}$ setembro de 2015.

VENCOVSKY, V. P. Ferrovia e logística do agronegócio globalizado: avaliação das políticas públicas e privadas do sistema ferroviário brasileiro. Tese (doutorado), UNICAMP, Instituto de Geociências. Campinas, SP., 2011. 